\title{
ENTERIJER SUŠI BARA U NOVOM SADU - ISTRAŽIVANJE PRIMJENE MOBILIJARA OD BETONA
}

\section{INTERIOR OF SUSHI BAR IN NOVI SAD - RESEARCH OF CONCRETE FURNITURE}

\author{
Mladenka Čajević, Fakultet tehničkih nauka, Novi Sad
}

\section{ARHITEKTURA I URBANIZAM}

Kratak sadržaj - Cilj ovog projekta jeste postizanje najboljeg enterijerskog rješenja suši bara sa akcentom na mobilijar. Kroz istraživanje betona kao materijala, dobijene su njegove ključne osobine $i$ proučene su njegove mogućnosti prilagođavanja enterijeru. Takođe, veliki fokus je stavljen na funkcionalnost datog rješenja, kao $i$ ambijentalnost. Nisu upotrijebljena obilježja Japanske kulture, ali se kroz raznovrsnost materijala $i$ čiste linije u prostoru oslikavaju karakteristike ove azijske hrane.

Ključne reči: Beton, Enterijer, Namještaj, Dizajn, Restoran, Kombinovanje

Abstract - The goal of this project is to achieve the best interior solution for a sushi bar with an emphasis on furniture. Through the research of concrete as a material, its key properties were derived, and its possibilities of adapting to the interior were studied. Also, great emphasis is placed on the functionality of the given solution, as well as the ambiance. No features of Japanese culture have been used, but the characteristics of this Asian food are reflected through the variety of materials and clean lines in the space.

Keywords: Concrete, Interior, Furniture, Design, Restaurant, Combination

\section{UVOD}

\subsection{Predmet istraživanja}

Tema ovog master rada jeste enterijersko rješenje restorana u okviru jednog od veoma važnih objekata u Novom Sadu. Detalje o temi, proces rada i sve smjernice koje su dovele do enterijerskog rješenja bara predstavljene su kroz ovo istraživanje.

U okviru ovog rada su spojene dvije teme, tačnije lična ljubav prema betonu i želja da se enterijer suši bara dizajnira na najbolji mogući način. Sva relativna mišljenja koja su doprinijela idejnom rješenju biće prikazana kroz tekstualni dio.

\subsection{Cilj rada}

Projekat je namjenjem stvaranju novih elemenata mobilijara i estetskih dodataka za domove $\mathrm{i}$ javne objekte. Ti

\section{NAPOMENA:}

Ovaj rad proistekao je iz master rada čiji mentor je bila prof. dr Ivana Miškeljin. elementi treba da budu primjer daljih intervencija i uvođenja novih i nesvakidašnjih materijala u prostore gdje se do tada nisu koristili. Takođe, sva istraživanja u ovom projektu su iskorištena za izradu idejnog rješenja suši bara, što je zapravo i tema rada.

\section{BETON}

\subsection{Opšti podaci o betonu}

Beton je građevinski materijal koji se dobija mješanjem nekog veziva (cementa, bitumena, asfalta, sadre...), agregata (pijeska, šljunka, tucanika...) i vode. Postoji više vrsta betona, a najčešće se klasifikuje prema gustoći gotove smjese ili prema vrsti veziva. Najčešće je u upotrebi beton s cementnim vezivom. Betonska mješavina miješa se u betonskoj mješalici. Mješavina se priprema na gradilištu ili, danas češće, u tvornicama betona (betonara), odakle se doprema vozilima na potrebne lokacije [1].

\subsection{Potencijali i ograničenja betona}

Velika je prednost betona što se u svježem stanju lako i po volji može oblikovati i taj oblik trajno zadržati nakon stvrdnjavanja. Odlikuje se i velikom čvrstoćom na pritisak (10 do $60 \mathrm{~N} / \mathrm{mm}^{2}$ ), ali mu je čvrstoća na zatezanje dosta manja. Manja čvrstoća na zatezanje nadoknađuje se ojačavanjem betona u zategnutim zonama pomoću čelične armature (armirani beton).

Čvrstoća betona označava se klasom (markom) betona. To je srednja vrijednost čvrstoće na pritisak betona starog 28 dana, mjerena na kocki sa stranicama debljine $20 \mathrm{~cm}$. Iako dosta dobro odolijeva atmosferskim uticajima, beton je zbog bazičnog sastava cementa neotporan prema kiselinama [1].

\section{STUDIJA SLUČAJA}

Kako bi mogli sagledati temu iz različitih uglova i dobiti najbolji i najprihvatljiviji zaključak odrađena je studija slučaja. Studija obuhvata nekoliko primjera iz grada, države i svijeta, u našem slučaju su to 3 predmetna komada, na osnovu čijih podataka i saznanja smo dobili uvid $\mathrm{u}$ neke osnovne tehničke, estetske i funkcionalne osobine mobilijara od betona.

\subsection{Gábor Kasza - Sekhina}

Interesantan primjer koji je obrađen u nastavku je nešta potpuno novo u svijetu dizajna, što nam daje nadu da vjerujemo da inovacije ipak i dalje postoje. Mađarski dizajnerski studio Sekhina predstavio je niz prekidača i 
utičnica izrađenih od betona kao alternativu plastici (Slika br. 1). Osnivač Sekhine, Gábor Kasza napravio je betonske prekidače i utičnice nakon što na tržištu nije uspio pronaći nijedan sličan proizvod izrađen od takvih materijala [2].

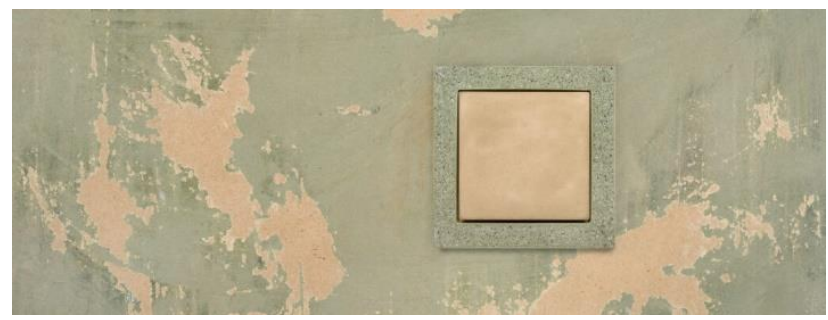

Slika br. 1 - prekidač od betona

\subsection{SLABS by design - Obi Dining Table}

Studio SLABS by design se godinama ozbiljno bavi dizajniranjem i proizvodnjom namještaja od betona, prije svega u kombinaciji sa prirodnim drvetom. Godišnje prikažu po nekoliko novih modela koji su dosta dobro prihvaćeni na tržištu. Ovaj studio nudi svojim mušterijama da uz njihove sugestije dizajniraju svoj komad namještaja, odrede strukturu betona, dimenzije koje su im potrebne i oblik koji im odgovara [3].

\subsection{Fernando Mastrangelo - "FMS"}

Fernando Mastrangelo dizajnirao je za sajam Art Genève 2016. klupu kao dio "FMS" kolekcije. Betonska klupa graniči između umjetnosti i modernog namještaja za svakodnevnu upotrebu (Slika 2). Sa jedne strane savršeno obrađena betonska površina, dok se na drugoj strani klupe nalazi djelimično obrađen beton, nalik na komad stijene. Ovakav namještaj može se vrlo dobro iskoristiti za uređenje enterijera ili za uređenje vrta, a svojom obradom prikazuje koliko je beton prilagodljiv i raznovrstan [4].

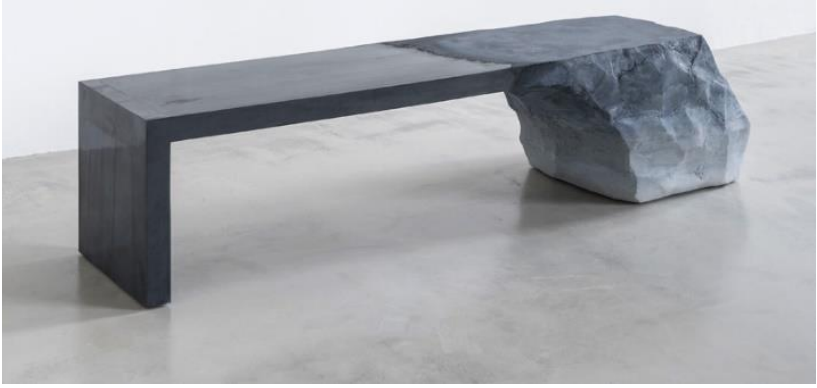

Slika br. 2 - prikaz betonske klupe "FMS"

\section{MOBILIJAR OD BETONA}

Pojam „betonski namještaj“ često podsjeća na nešta izuzetno teško, hladno, pogodno samo za sjedenje u parkovima i na autobuskim stajalištima. Ali dizajneri već duže vrijeme shvataju da namještaj od betona može biti jednako moderan, elegantan, gotovo kao lagan i daleko trajniji od ostalih materijala.

Iako ne toliko zastupljen ipak se primjeti dosta veće prisustvo ovog materijala na nekim elementima $u$ enterijeru za razliku od prije nekoliko godina. Sve je počelo sa zidovima koji su ćesto u javnim objektima, prije svega zbog uštede, ostavljani ne obrađeni i sa vidnom grubom teksturom betona. To vremenom prerasta u dosta ozbiljniju i elegantniju priču gdje dizajneri, školovani ili samouki na tom parčetu zida otkrivaju mogućnost raznih kombinacija završnih obrada.

Iz obične, nekada nedopustive grube konstrukcijske slike sada nastaje novi trend. Polako i drugi elementi enterijera primaju tu notu sivila i stvaraju se i drugi elementi od betona.

Prije svega u ugostiteljskim objektima ovu „modu“ možemo vidjeti na nekim komadima namještaja ili detaljima enterijera. Takođe, pod pojmom „namještaj“ ne ubrajamo samo stolice i stolove, tu idemo korak dalje i dizajniramo rasvjetna tijela, žardinjere, satove, ramove slika, ... (Slika br. 3)

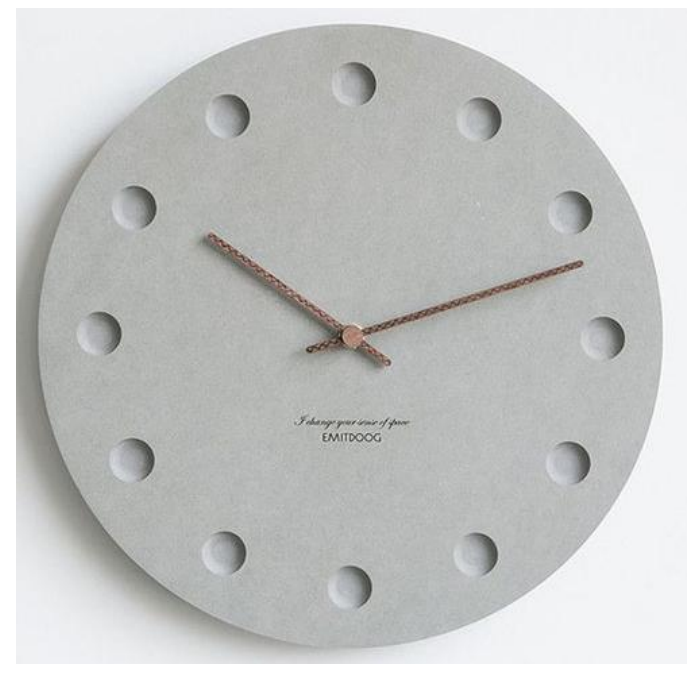

Slika br. 3 - betonski sat

\subsection{Dobijeni efekti i estetika}

Materijali s izraženom strukturom, prostoru daju dodatnu dubinu. Tako i beton svojom grubom strukturom stvara vizuelni interes. Međutim, svaki beton nije jednak. Neke vrste imaju izraženiju i grublju strukturu, dok druge vrste imaju zanimljive diskoloracije.

Struktura betona se najjednostavnije može naglasiti stvaranjem kontrasta. Tako beton najviše dolazi do izražaja kad je suprotstavljen nekom prirodnom materijalu, kao što je drvo. Kontrast se može stvoriti i ostatkom boja u prostoru koje najbolje odgovaraju nijansama betona.

Čvrstoća i čiste linije betona dobro se razlikuju od mekog namještaja.

Beton takođe može poprimiti gotovo bilo koji oblik, boju, više različitih tekstura $\mathrm{i}$ mnoštvo različitih otisaka. To je jedan od najsvestranijih materijala za namještaj, s njegovom kombinacijom snage i slobode izgleda. Završna obrada može da bude mat ili sjajna, industrijski ili zabavan i umjetnički. 


\section{LOKACIJA I POSTOJEĆE STANJE}

Nekada je „Stoteks“ bila najveća robna kuća u Novom Sadu i Vojvodini, a već tada se smatrala jednom od najljepših trgovačkih kuća u nekadašnjoj Jugoslaviji. Projektovao ju je arhitekta Milan Mihelič, 1972. godine u modernističkom stilu sa jasnim arhitektonskim obilježjima ideologije tog vremena. $U$ to vrijeme smatrana je za najbolje slovenačko arhitektonsko djelo modernog doba. Robna kuća otvorena je zvanično 1984. godine, a od tada je više puta mijenjala ime. Danas se zove, tržni centar Bazaar, a od otvaranja do 1994. godine nosila je naziv „Novi Sad”.

Zanimljiv podatak vezan za temu rada jeste da je fasada objekta trebala biti od betona, ali u zadnjem momentu je investitor dao prijedlog arhitekti da to ipak budu kamene ploče, što je Milan Mihelič prihvatio. Lokal koji se obrađuje u ovoj temi se nalazi u prizemlju ranije navedenog tržnog centara, desno pored južnog ulaza u objekat i nosi zvaničnu oznaku P3.3.

Trenutno je prostor pod zakupom Sephora trgovine za kozmetiku i njegu kože. Oblik samog prostora je dosta neobičan, iako je u osnovi pravougaonik podijenjen je na dvije cjeline zbog pokretnih stepenica koje jednim dijelom prolaze kroz njega.

Ukupna površina lokala je oko $224,24 \mathrm{~m}^{2}$, a spratna visina je $5 \mathrm{~m}$. Visina se zavisno od namjene prostora koriguje spuštenim plafonima, a pregradni zidovi su nezavisni od konstrukcije pa se mogu izmiještati ili uklapati prema potrebi zakupoprimac.

\section{PISMENA ANKETA}

Za svrhu rada sprovedena je anketa od 01.09.2020. godine do 30.09.2020. Anketu su popunjavala punoljetna lica različitih godina, interesovanja i životnih iskustava.

Prije svega je kroz ovo malo istraživanje potvrđeno da svi imaju isto mišljenje o betonu kao hladnom materijalu.

Dosta razočaravajući podatak jeste da su veoma rijetko ispitanici viđali i/ili koristili mobilijar od betona. A oni koji jesu navode da su to prije svega najklasičnije klupe u parkovima i na trgovima, koje pretežno izbjegavaju da koriste zbog hladnog osjećaja.

Sa druge strane veoma osvježavajući rezultat ankete jeste da veliki broj ispitanika smatra da se beton može koristiti više u enterijeru, da bi rado koristili takve prostore i da su otvoreni da eksperimentišu $i$ borave $u$ takvim ambijentima. Veliki broj ispitanika je imao i jasan stav što se tiče vrste lokala gdje se beton može/treba upotrijebiti. Prije svega to su suši bar, pasta bar i picerija.

\section{IDEJNO RJEŠENJE}

\subsection{Prostorna organizacija}

Pokušavajući osmisliti najidealnije rješenje za ovaj prostor dolazilo je do različitih podjela cjeline. Olakšicu predstavljaju već zadati parametri na koje nismo mogli uticati, oblik prostora u osnovi, stakleni portali i ulaz u lokal koji je morao biti sa zapadne strane.

Prvi korak projektovanja je bila podjela prostora u dvije zone:
1. Zona za pripremu hrane i osoblje

2. Zona za korisnike usluga bara

Nakon toga je slijedila podjela zona na prostorije koje je svaka od njih morala da sadrži.

Zona za pripremu hrane i osoblje:

1. Kuhinja

2. Rashladna komora

3. Ostava za namjernice

4. Ženska svlačionica

5. Muška svlačionica

6. Ulaz za zaposlene

Zona za korisnike usluga bara:

1. Bar

2. Šank

3. Toaleti za goste sa ostavom

\subsection{Koncept i obrazloženje ideje}

Koncept samog projekta je bio odmah jasan, uvesti beton u enterijer i osmisliti inventar koji će u isto vrijeme biti nesvakidašnji, funkcionalan i koji će zadovoljavati potrebe bara (Slika br. 4).

Materijalizacija. Nakon riješene funkcije slijedi zanimljiviji dio projektovanja, a to je svakako dizajn prostora. Kao što je kroz rad već naglašeno, glavni materijal koji ćemo koristiti za uređenje enterijera je beton. $U$ istraživanju je zaključak jasan, drvo i beton su najidealnija kombinacija, ali mi idemo korak dalje, kao što je japanska kuhinja raznovrsna, tako ćemo i mi u enterijeru pomoću raznovrsnih materijala indirektno naglasiti tu karakteristiku ove hrane.

Pored betona u različitim načinima primjene i izvedbe, u enterijeru ćemo koristiti i puno orahovo drvo. Sama struktura oraha i prirodna boja su prijatan prizor za oko posmatrača, što smo mi i iskoristili. Pored navedena dva materijala, na nekim od konstruktivnih" elemenata korišćena je opeka. A sve veze, neophodne oslonce i detalje je planirano da se urade od metala, bilo to da su profili, cijevi, flahovi, zavisno od funkcije prilagođeni su prostoru.

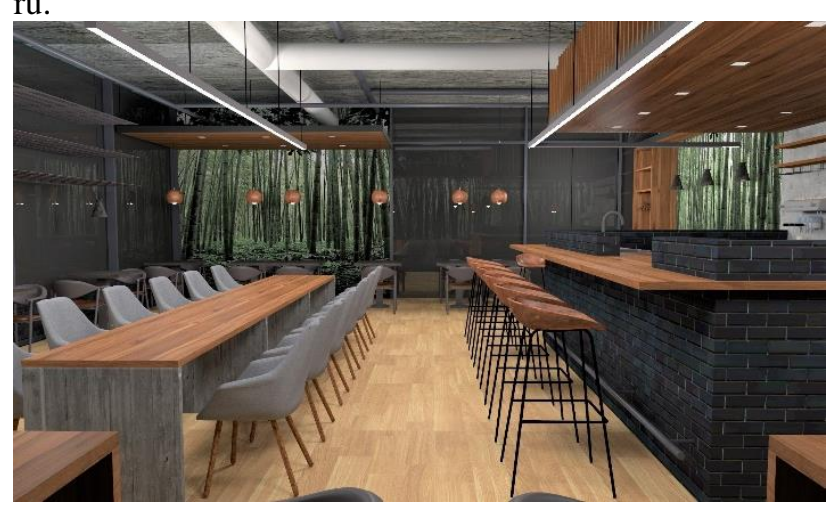

Slika $4-3 D$ prikaz

Boja oraha će dominirati u prostoru, a zajedno sa tapaciranim elementima obloženim pravom smeđom kožom je zaokružena ova priča. 
Ambijenti. U prostoru će ostati vidne instalacije pri plafonu, a na samom plafonu će biti završna obrada od grubo našpricanog razrijeđenog betona. Kako bi se na indirektan način razbio prostor kao cjelina, poigraćemo se psihom posmatrača. Određeni ambijenti su dobijeni postavljanjem visećih plafona od iverala i punog drveta, $\mathrm{i}$ armaturnih ploča na nekim dijelovima bara (Slika 5). Tako su bez postavljanja pregrada na elegantan način dobijene manje cjeline $\mathrm{u}$ prostoru koje su opet objedinjene.

Rasvjeta. Akcenat je stavljen i na rasvjetu. Različitim tehnikama osvjetljenja istaknuti su određeni dijelovi bara. Pored direktnog osvjetljenja sa plafona, dosta su korištene visilice koje su postavljane iznad svakog stola, samim tim se dodatno naglasila intima određenih mjesta.

Zidovi su na nekim dijelovima samo omaltani, dok je na velikom dijelu postavljena tapeta. Tapeta sa slikom šume bambusa u prigušeno zelenoj nijansi je jedino obilježje koje nas može asocirati na daleki istok.

Beton kao materijal je korišten na nekim elementima mobilijara, može se primjetiti na zidovima kao završna obrada, kao oslonac na centralnom stolu, kao ploča na zasebnim stolovima i kao poseban detalj isturene obloge zida.

Prostor pruža raznovrsnost po svim aspektima. Sjedenje na barskim stolicama za šankom ili u mirnijem dijelu bara, klasično sjedenje za 2, 3 ili 4 osobe, ili druženje za centralnim stolom koje može da dovede i do novih poznanstava ili neobaveznog razgovora sa osobom koja slučajno sjed do vas.

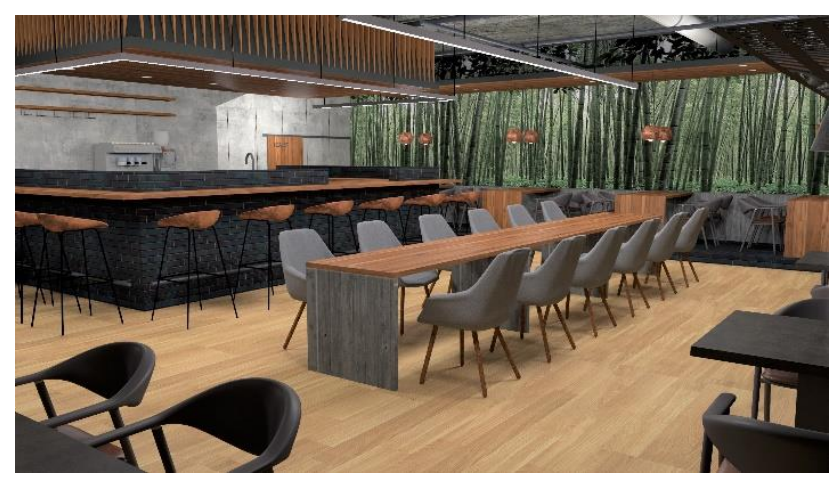

Slika 5 - 3D prikaz

\section{ZAKLJUČAK}

$\mathrm{Na}$ kraju ovog istraživačkog i projektantskog rada, potrebno je reći da postoji još mnogo toga što se može izvući iz betona kao materijala. Ima dosta toga vrijednog što možemo da stvorimo i damo to kao doprinos našem društvu i našoj sredini. Ovo znanje može u mnogome da posluži i van ove sfere uslužnih objekata.

Istraživanje prikazano ovim radom je samo dio onoga šta od betona možemo stvoriti. Svakako da je suši bar nešta novo u gradu Novom Sadu, ali takođe smatram da su građani kao i turisti našeg grada otvoreni za nove ekspirimente i avanture sa ovom vrstom azijske hrane.

\section{LITERATURA}

[1] Ivan Tomić, Betonske konstrukcije, Školska knjiga Zagreb, 1988

[2] https://www.mojstan.net/namjestaj-

dekoracije/betonski-prekidaci-i-uticnicel

[3] https://www.handkrafted.com/slabsbydesign/1042438/ slabs-by-design-obi-dining-table

[4] https://www.mojstan.net/namjestajdekoracije/betonska-klupa-za-interijer-i-eksterijer/

\section{Kratka biografija:}

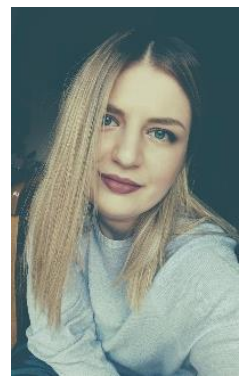

Mladenka Čajević rođena je u Palama 1993, god. Master rad na Fakultetu tehničkih nauka iz oblasti Arhitektura i urbanizam Projektovanje enterijera 3 odbranila je 2020. godine. 